\section{$\underset{\text { hommes }}{\text { \& migrations }}$}

\section{Hommes \& migrations}

Revue française de référence sur les dynamiques

migratoires

1302 | 2013

Le Japon, pays d'immigration?

\title{
Goodbye Morocco
}

Film français de Nadir Moknèche

\section{Anaïs Vincent}

\section{Q OpenEdition \\ 1 Journals}

\section{Édition électronique}

URL : http://journals.openedition.org/hommesmigrations/2504

DOI : 10.4000/hommesmigrations.2504

ISSN : 2262-3353

\section{Éditeur}

Musée national de l'histoire de l'immigration

\section{Édition imprimée}

Date de publication : 1 avril 2013

Pagination : 183-185

ISBN : 978-2-919040-22-3

ISSN : $1142-852 X$

\section{Référence électronique}

Anaïs Vincent, "Goodbye Morocco », Hommes \& migrations [En ligne], 1302 | 2013, mis en ligne le 09 mai 2014, consulté le 22 septembre 2020. URL : http://journals.openedition.org/hommesmigrations/ 2504 ; DOI : https://doi.org/10.4000/hommesmigrations.2504 


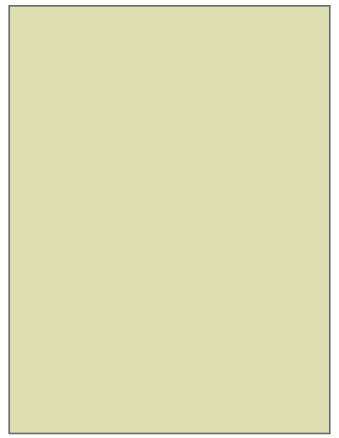

\section{Anaïs Barbeau- Lavalette \\ Inch'Allah \\ Film franco-canadien (Québec)}

Chloé, une jeune obstétricienne de nationalité canadienne (Évelyne Brochu), exerce en tant que volontaire dans un dispensaire humanitaire de Cisjordanie sous les ordres d'un médecin français.

Elle s'occupe notamment, dans un camp de réfugiés, d'assister et de conseiller des femmes palestiniennes enceintes. Cette grande idéaliste, venant d'un pays traditionnellement neutrequia toujours accueilli des immigrants et des réfugiés du monde entier, ne se doute pas en arrivant in situ de la tension explosive qui règne aux abords de la frontière avec Israël où elle sera affectée par une ONG. Tous les soirs, elle rejoint son appartement du côté israélien en franchissant le mur de séparation. Loin de ses propres racines et sans vouloir prendre parti pour l'un des États en conflit, la praticienne québécoise se lie d'amitié avec Ava (Sivan Levy), sa voisine de palier, soldate israélienne du checkpoint chargée de filtrer sans ménagement les entrées et sorties des Territoires occupés.

Chloé sympathise aussi avec Rand (Sabrina Ouazani), une de ses patientes arabes, et tombera amoureuse de son frère Faysal (Yousef Sweid), activiste palestinien employé dans une imprimerie. Dans un climat d'indescriptible insécurité, ces trois femmes échangeront d'émouvantes confidences sur leurs désirs et leurs aspirations complexes, voire antinomiques, dans des sociétés phallocrates ou des régimes théocratiques. Sans être la proie du prosélytisme de ces rencontres qui expriment chacune "leur" vérité, Chloé essaye de garder une ferme neutralité. Progressivement, son esprit oscille entre l'amour pour Faysal le militant engagé et les arguments soutenus par Ava à propos des menaces d'attentats antisémites pesant sur Israël, justifiant ainsi les sévères représailles de Tsahal contre les rebelles.

L'impartialité qui l'habitait à son arrivée en Palestine sera mise à rude épreuve par divers attentats auxquels elle assiste. Ses attaches des deux côtés du mur la plongeront dans un dilemme.

Sonrefusd'alimenterunehainefratricide tiendra-t-il ? Les suspicions et la défiance qu'inspire chez les belligérants cette "étrangère" ne cessent de croître car elle refuse de prendre position malgré les pressions qu'elle subit. Sans être impliquée politiquement, elle continuera d'accomplir sa mission, motivée principalement par sa vocation de "médecin du monde", portant secours à tous ceux qui souffrent, quel que soit leur credo.

Cependant, de douloureux incidents, comme la mort révoltante d'un enfant écrasé par un char israélien et une brutale confrontation avec un militaire qui coûtera la vie au nouveau-né de Rand, feront basculer Chloé dans un des camps. Est-ce pour l'amour d'un guerrier, en vertu d'une idéologie, ou bien en réaction aux atroces scènes dont elle a été le témoin, qu'elle accomplira un acte aussi barbare que ceux que l'on reproche à l'ennemi, afin d'établir une supposée justice? 
La fin troublante et brutale du deuxième long métrage d'Anaïs Barbeau-Lavalette (après Le Ring en 2007), rappelle à quel point l'intolérance ou l'injustice, au même titre qu'un fanatisme aveugle, peuvent métamorphoser une personne en bourreau. L'attentat kamikaze estil l'ultime recours d'un combattant pour défendre sa cause? Ce film pose

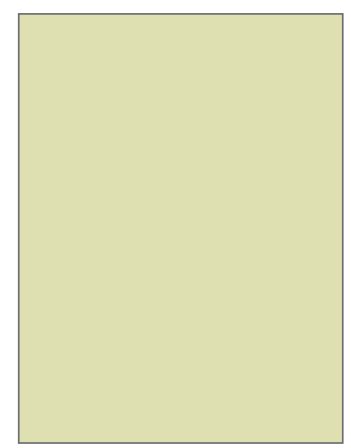

\section{Nadir Moknèche \\ Goodbye Morocco \\ Film français}

Les 4 et 5 Juin, Rabat a accueilli une conférence sur le thème : "Transition et égalité des genres dans les pays arabes, progrès ou régression ?" C'est l'occasion de débattre et de faire le point sur cette question d'actualité alors que la jeune Femen tunisienne, Amina, est toujours en détention. Malgré les progrès indéniables réalisés du point de vue de l'éducation et de la de nombreuses questions sans manichéisme. Le talent des acteurs, une direction artistique précise, ainsi que la reconstitution exacte du mur de séparation et de ses alentours, confèrent à cette fiction une authenticité proche du documentaire, permettant d'avoir une vision plus objective de cet éternel conflit. Thomas Namer

santé des femmes, le chemin est encore long. Cette question de la place des femmes au sein du monde arabe est le sujet de prédilection du réalisateur franco-algérien Nadir Moknèche. Né à Paris, à la mort de son père, il part vivre avec sa mère à Alger. Il est alors âgé de 3 ans. À l'adolescence, il retourne en France. Après son baccalauréat et deux années de droit, il étudie les arts dramatiques et le cinéma à New York. Dans sa filmographie, Nadir Moknèche dépeint la complexité de la société algérienne. La figure matriarcale est au cœur de ses récits. Dounia, l'héroïne de son dernier film Goodbye Morocco, est l'une d'entre 
elles. Cette jeune mère divorcée tient d'une poigne de fer les rênes d'une entreprise en bâtiment à Tanger avec son nouvel ami, un architecte serbe. Sur l'un de leurs chantiers, les ouvriers mettent au jour une ancienne sépulture décorée d'une fresque antique. Avec la vente frauduleuse de ce trésor archéologique, Dounia espère enfin concrétiser son rêve le plus cher : fuir le Maroc avec son fils et son amant. Mais tout ne se déroulera pas comme prévu...

Nadir Moknèche construit un drame d'une profonde noirceur. Son polar nous conduit sur les traces de ces harragas prêts à tout pour gagner des terres plus clémentes. II dresse un portrait sombre d'une société gangrenée par la corruption, dans laquelle la femme peine à s'émanciper.

Cette fiction se déroule au Maroc mais aurait tout aussi bien pu se passer en Algérie si le réalisateur n'avait pas été sanctionné par une interdiction de tournage après la réalisation de Délice Paloma, où il dénonçait la corruption algérienne. À nouveau, il révèle ici une administration vérolée par la malhonnêteté.

Après la décolonisation, le Maghreb a été plongé dans la frénésie de l'économie de marché. La lutte anticorruption était le fer de lance de la campagne électorale des islamistes au Maroc.

Mais les résultats sont encore mitigés. L'opacité du système demeure.

Dounia profite de ses failles. Elle souhaite de tout son cœur fuir sa terre natale. Elle s'engage alors dans un commerce juteux, celui du trafic d'œuvres d'art, très lucratif en Afrique. Malgré la réglementation de l'Unesco depuis la coloni- sation, de nombreux pays ont été pillés en toute impunité. Avec la décolonisation, certaines œuvres ont été restituées en signe d'apaisement politique et de réparation des crimes commis. Mais le trafic illégal d'œuvres reste cependant très actif.

Dounia contourne également la loi en embauchant au noir sur son chantier des ouvriers clandestins d'origine sénégalaise et nigérienne. Comme le révèle un récent rapport établi par Médecins sans frontières (MSF), des voyageurs souvent originaires d'Afrique subsaharienne en transit au Maroc en vue de rejoindre l'Europe sont de plus en plus victimes de violences criminelles et institutionnelles. Le durcissement de la politique migratoire de Bruxelles est mis en cause. Nadir Moknèche dénonce les conditions de travail et de vie de ces ouvriers exploités. Pour survivre et bientôt fuir, ces harragas acceptent les pires humiliations au péril de leur vie. Ainsi, le jeune Gabriel tombe dans le filet de la prostitution et du vol. Dounia n'a aucune compassion pour ces employés qui pourtant, comme elle, aspirent à partir dans l'espoir d'une vie meilleure.

La filmographie de Nadir Moknèche se construit autour de personnages féminins emblématiques, dont il révèle la fragilité. Si le Maroc a adopté des lois affirmant la parité sur le marché du travail, la réalité est tout autre. Le gouvernement a pourtant ratifié la Convention internationale sur l'élimination de toutes les formes de discriminations à l'égard des femmes. Mais elles restent bien plus touchées par le chômage que les hommes et sont encore très rares aux postes de direction. Moknèche choisit comme 
héroïne l'une d'elles.Dounia semble être l'exemple même de la femme marocaine émancipée. Elle est parvenue à quitter son mari, fréquente un jeune Serbe, dirige une entreprise. Lubna Azabal interprète avec justesse cette femme prête à tout pour vivre sa vie comme elle l'entend et enfin connaître la liberté. Mais, malgré sa volonté d'échapper aux

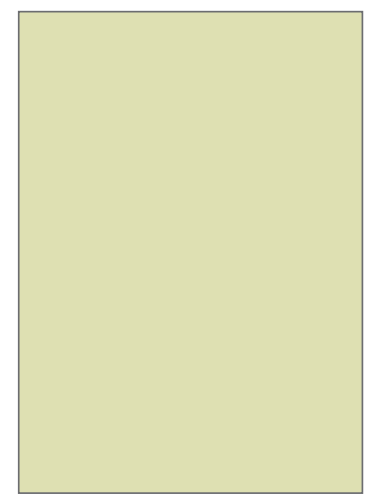

Shola Lynch

Free Angela and All Political

Prisoners

Documentaire américain

Free Angela est le deuxième documentaire de la réalisatrice et productrice américaine Shola Lynch. Comme dans son précédent film sur la députée Shirley Chisholm, elle se confronte à la biographie d'une icône afro-américaine.

À travers le récit de ce destin personnel, elle met en lumière la force de l'engagement et du combat contre la discrimination raciale de la militante féministe communiste afro américaine Angela Davis.

La jeune Angela décide très tôt de lutter contre l'injustice qui frappe sa communauté. Elle étudie la philosophie en France puis en Allemagne. Elle se familiarise avec les thèses de Marx et adhère rapidement au communisme. La libération du peuple noir doit sefaire, selon elle, avec les outils du socialisme. Depuis l'Europe, elle entend la contestation des diktats de cette société patriarcale, elle sera rattrapée par son destin.

Le cinéaste porte un regard pessimiste sur l'évolution de la condition féminine dans ce pays.

Le 13 février dernier sortait sur nos écrans ce dernier film de Nadir Moknèche. À partir du 13 juin, on pourra le trouver en DVD. Anaïs Vincent

défenseurs des droits civiques prendre de l'ampleur dans son pays. Pour être au cœur des revendications, elle décide de rentrer. Elle milite au sein des Black Panthers, puis rejoint le Che-Lumumba Club, mais s'indigne contre la misogynie présente dans ces mouvements. Pour elle, le combat pour le respect des droits de la minorité noire n'a aucune chance d'être victorieux si les femmes restent asservies. Devenue professeur de philosophie à l'université de Californie, elle est radiée quelque temps plus tard pour ses opinions politiques. Elle se mobilise à corps perdu pour la libération de George Jackson, Fleeta Drumgo et John Clutchette, les "Frères de Soledad". Tout bascule quand elle est accusée d'avoir fomenté leur évasion qui coûte la vie à un juge. Dans les années 1970, J. Edgar Hoover, directeur du FBI, souhaite museler les leaders de ces mouvements protestataires. Des méthodes très contestables sont alors utilisées. Le Cointelpro (Counter Intelligence Program), un programme de contre-espionnage, infiltre ces organisations et met en place des procès à charge pour discréditer leurs militants. Dans ce climat de terreur, pour Angela 
Davis, la seule alternative est la cavale. Elle est finalement arrêtée et emprisonnée pendant vingt-deux mois. Jugée lors d'un long procès, elle sera acquittée grâce à la mobilisation internationale. Ce combat est raconté sans voix off, avec des extraits de films d'archives et des interviews. La parole des protagonistes jalonne ce récit. Ils reviennent tour à tour sur la xénophobie latente des instances politiques des années 1970, sur les injustices dont sont victimes les Afro-Américains et expliquent de quelle manière l'action de chacun a été déterminante. Mais avant d'être le témoignage d'une lutte historique, ce film montre comment la mobilisation peut permettre de gagner un combat. La réalisatrice insuffle un vent d'espoir dans le marasme de notre génération désenchantée. Alors que les mouvements d'extrême droite reprennent de l'ampleur, que le capitalisme laisse chaque jour derrière lui des millions de désœuvrés, I'histoire d'Angela Davis nous rappelle notre devoir de citoyen de lutter contre toute forme d'injustice et souligne le pouvoir de la contestation de masse.

Aujourd'hui, même si des travaux d'historiens et certaines révélations ont permis de mettre en lumière les abus de la politique de J. Edgar Hoover, certaines zones d'ombre demeurent encore au tableau.

Le 18 mai 2013, le nom d'Assata Shakur, la tante du célèbre rappeur Tupac Amaru Shakur (2Pac), une militante des droits civiques, ancienne membre des Black Panthers, figure désormais sur la liste des terroristes les plus recherchés aux États-Unis pour des faits remontants à 1971. Cette présumée ennemie du Pentagone est accusée d'avoir tué un policier dans une fusillade dans laquelle elle fut elle-même blessée. Elle est à l'époque condamnée à la prison à vie. 
Mais aucune preuve ne permet de proclamer sa culpabilité. En 1979, avec l'aide desonfrère,elles'évade. Elle se réfugieen 1984 à Cuba où elle réside actuellement. Comparer cette exilée à des djihadistes forcenés semble absurde.

Cette militante n'a pas bénéficié de la même médiatisation qu'Angela Davis ni de la même mobilisation autour de sa cause. Comme le souligne l'héroïne du film de Shola Lynch, aujourd'hui il faut

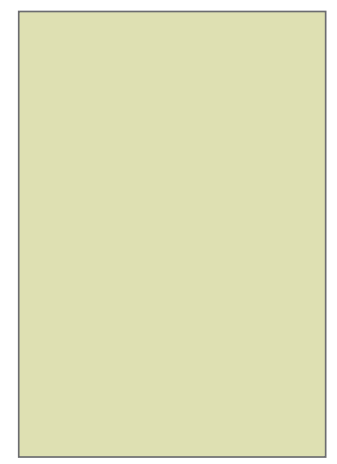

\section{Katsuya Tomita}

Saudade

Film japonais

Saudade, un titre portugais pour un film japonais, parce qu'il s'agit de parler des villes japonaises dont l'activité s'est maintenue -untemps-grâceà l'immigration brésilienne. Saudade, peut-être aussi parce qu'il s'agit aujourd'hui de villes durement touchées par les crises économiques et dont la population diminue, laissant les centres villes désolés pour ceux qui restent et cherchent du travail, des amis ou du rêve. Saudade se passe dans les rues d'une de ces villes, Kôfu, qui ressemble à beaucoup d'autres dispersées entre Tokyo et Nagoya, le coeur industriel du pays. Plus que d'autres régions, les entreprises sous-traitantes des grands groupes ont eu recours, dans les années 1990, à une main-d'oeuvre très flexible de décendants de Japonais venus d'Amérique latine. remettre de la patience au cœur de la politique.

On ne peut pas se mobiliser une journée et puis plus rien. Les grands combats nécessitent du temps et de l'obstination. Free Angela and All Political Prisoners est une belle leçon de pugnacité, tant pour le choix de son sujet que pour sa réalisation. Il a fallu pas moins de huit ans pour que ce biopic puisse voir le jour.

Anaiis Vincent

Comme ailleurs, et depuis les années 1980, les bars à hôtesses ont largement recruté dans les pays asiatiques.

saudade parle de ces villes périphériques, pas toujours bien connues des Japonais eux-mêmes, où la population étrangère est beaucoup plus visible que sur l'ensemble du territoire japonais. Le film parle des rencontres et des nonrencontres entres habitants japonais et étrangers, de l'attirance et du rejet : histoire d'amour entre un ouvrier japonais et une hôtesse thailandaise, histoire de rivalité entre groupes de hip hop japonais et nippo-brésilien. II parle de leur communauté de destin face à la crise économique, mais aussi des rêves divergents, de ceux qui partent, repartent ou rêvent de partir, de ceux qui restent.

Mal du pays, mal être, nostalgie d'une époque plus florissante,Saudadesignifie sûrement tout cela à la fois, en prenant trois heures pour entrecroiser les vies de personnages, tous plus ou moins marginaux et à la recherche de leur identité. Hélène Le Bail

Film sorti au Japon en 2011, sorti sous-titré en France en 2012 (Alfama Film) 